\title{
EXPRESS Rack Technology for Space Station
}

\author{
Ted B. Davis ${ }^{1}$, J. Brian Adams ${ }^{2}$, Edward M. Fisher Jr. ${ }^{3}$, Guy B. Prickett ${ }^{4}$, \\ Timothy G. Smith ${ }^{5}$
}

The Boeing Company, 499 Boeing Blvd., Huntsville, AL 35824

[Phone: 256-961-4522 ; 256-961-1552 ; 256-961-4981 ${ }^{3} ; 256-961-3045^{4} ; 256-961-5522^{5}$ ]

\begin{abstract}
The EXPRESS rack provides accommodations for standard Mid-deck Locker and ISIS drawer payloads on the International Space Station. A design overview of the basic EXPRESS rack and two derivatives, the Human Research Facility and the Habitat Holding Rack, is given in Part I. In Part II, the design of the Solid State Power Control Module (SSPCM) is reviewed. The SSPCM is a programmable and remotely controllable power switching and voltage conversion unit which distributes and protects up to $3 \mathrm{~kW}$ of 120 VDC and 28VDC power to payloads and rack subsystem components. Part III details the development and testing of a new data storage device, the BRP EXPRESS Memory Unit (BEMU). The BEMU is a conductioncooled device which operates on 28VDC and is based on Boeing-modified 9GB commercial disk-drive technology. In Part IV results of a preliminary design effort for a rack Passive Damping System (PDS) are reported. The PDS is intended to isolate ISPR-based experiment racks from on-orbit vibration. System performance predictions based on component developmental testing indicate that such a system can provide effective isolation at frequencies of $1 \mathrm{~Hz}$ and above.
\end{abstract}

\section{PART I: EXPRESS RACK AND ITS DERIVATIVES}

The EXpedite the PRocessing of Experiments to Space Station (EXPRESS) Rack provides accommodations that simplify and expedite analytical and physical integration of International Space Station (ISS) subrack payloads. The EXPRESS Rack is an International Standard Payload Rack (ISPR) modified to provide standard mechanical, data, power, and thermal cooling interfaces to payload developers. As shown in Figure 1, it provides space for eight standard Mid-Deck Lockers (Shuttle compatible), two 4-Panel Unit International Subrack Interface Standard (ISIS) drawers, 2000 Watts of 28 VDC power to payloads, RS-442, Ethernet, MIL-STD-1553, and video data interfaces.

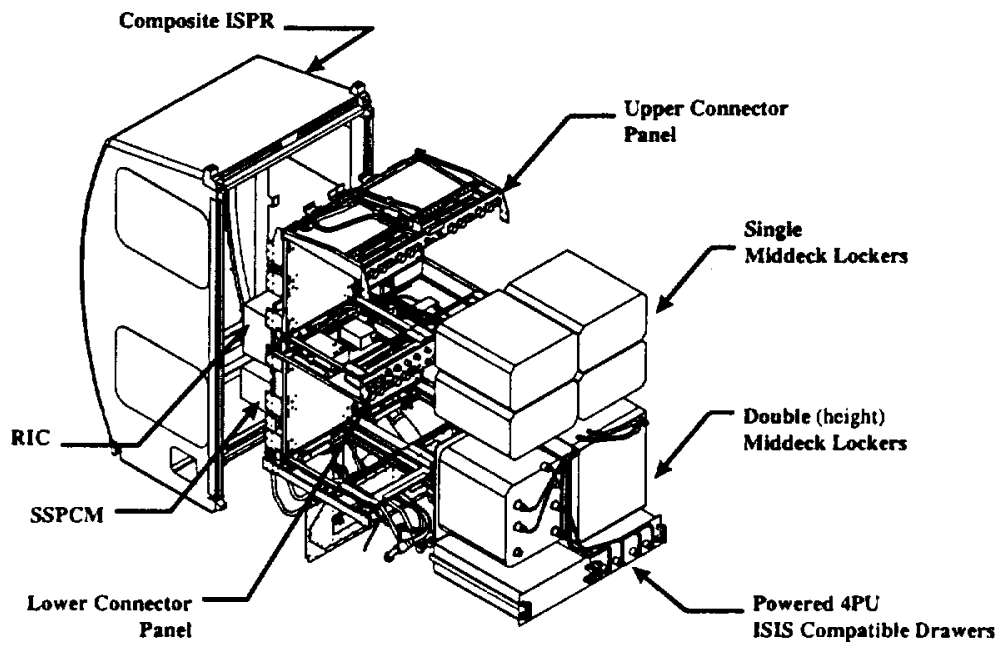

Figure 1. EXPRESS Rack 
The EXPRESS Rack consists of an ISPR, a Solid State Power Controller Module (SSPCM), an EXPRESS Memory Unit (EMU), a Payload Ethernet Hub/Bridge (PEHB), a Rack Interface Controller (RIC), a laptop computer, various types of Payload Interface Equipment (PIE) including structure, ducting and tubing, an EXPRESS Utility Drawer, and miscellaneous electrical and structural/mechanical hardware elements. The rack can be functionally divided into the following subsystems: power distribution system, thermal control system, and command and data handling system. The rack also provides access for the vacuum exhaust system and nitrogen system.

The Human Research Facility (HRF) rack, Figure 2, and the Biological Research Project (BRP) rack, Figure 3, are all-drawer configuration derivatives of the basic EXPRESS Rack.

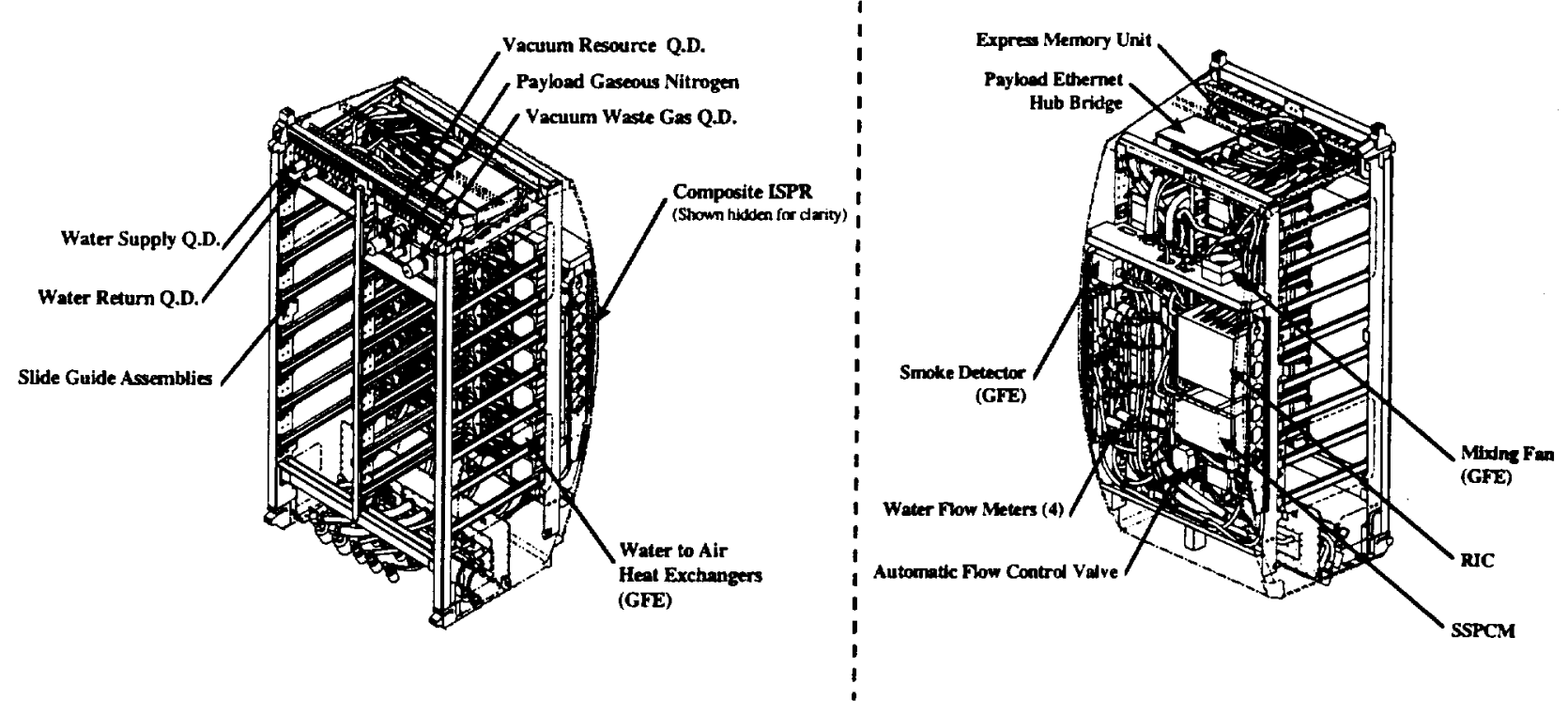

Figure 2. Human Research Facility Rack

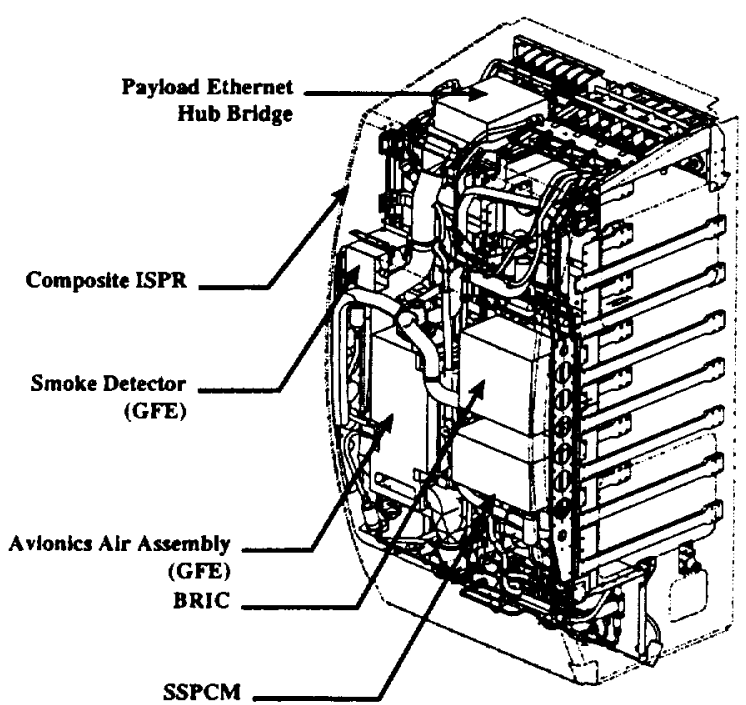

Figure 3. Habitat Holding Rack-Biological Research Program 
The EXPRESS Rack provides at least 2 kilo Watts $(\mathrm{kW})$ of total power to the complement of payloads with the rack. The power provided to payloads is $28 \mathrm{vdc}$ on 5, 10,15, and $20 \mathrm{amp}$ Solid State Power Controllers (SSPCs). The rack power technology is explained in Part II, below.

The EXPRESS Rack interfaces to the ISS Internal Thermal Control System (ITCS) Moderate Temperature Loop (MTL) to reject up to 3000 Watts (W) of heat from the rack subsystems and payloads. The maximum return coolant temperature from the rack to the host module MTL shall not exceed $120^{\circ} \mathrm{F}$. The EXPRESS Rack is capable of accepting at least $2000 \mathrm{~W}$ of heat from the complement of payloads. The EXPRESS Rack provides two sets of MTL water interfaces (supply and return) at the front face of the rack, each capable of flowing from 50 to $300 \mathrm{lbm} / \mathrm{hr}$ of MTL water. The thermal subsystem (air and water) is denoted in Figures $4 a$ and $4 b$.

The Command and Data Handling (C\&DH) systems (Figure 5) provides payload commanding, health and status reporting, video and telemetry service.

The data interfaces includes 10 Base T IEEE 802.3, Ethernet interface in accordance with IEEE standard 802.3, which provides a payload connection to the "rack to rack" LAN through the PEHB. Thus, the payload can communicate directly with the RIC or another payload within the same Rack. The RIC also provides a RS-422 data interface which consists of a 4-wire (TX +/- and RX +/-), selectable Baud Rate $1200,2400,9600,19.2 \mathrm{~K}$, and $38.4 \mathrm{~K}$, with duplex asynchronous operation.

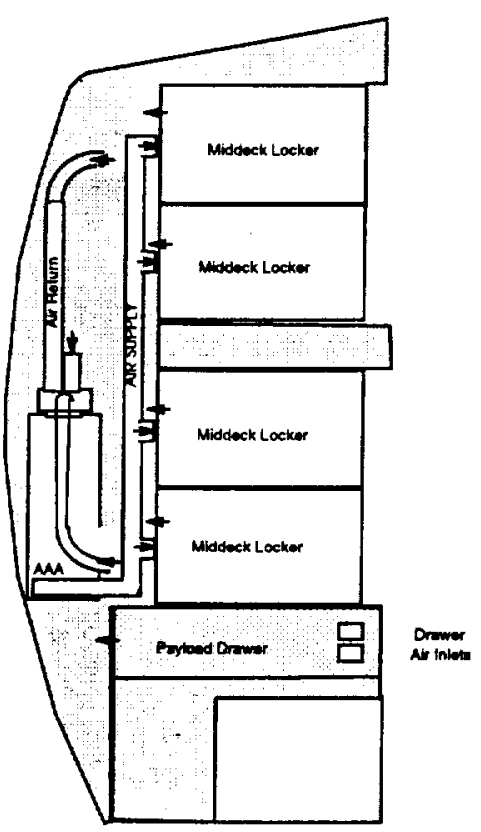

Figure 4a. Air Flow Schematic 


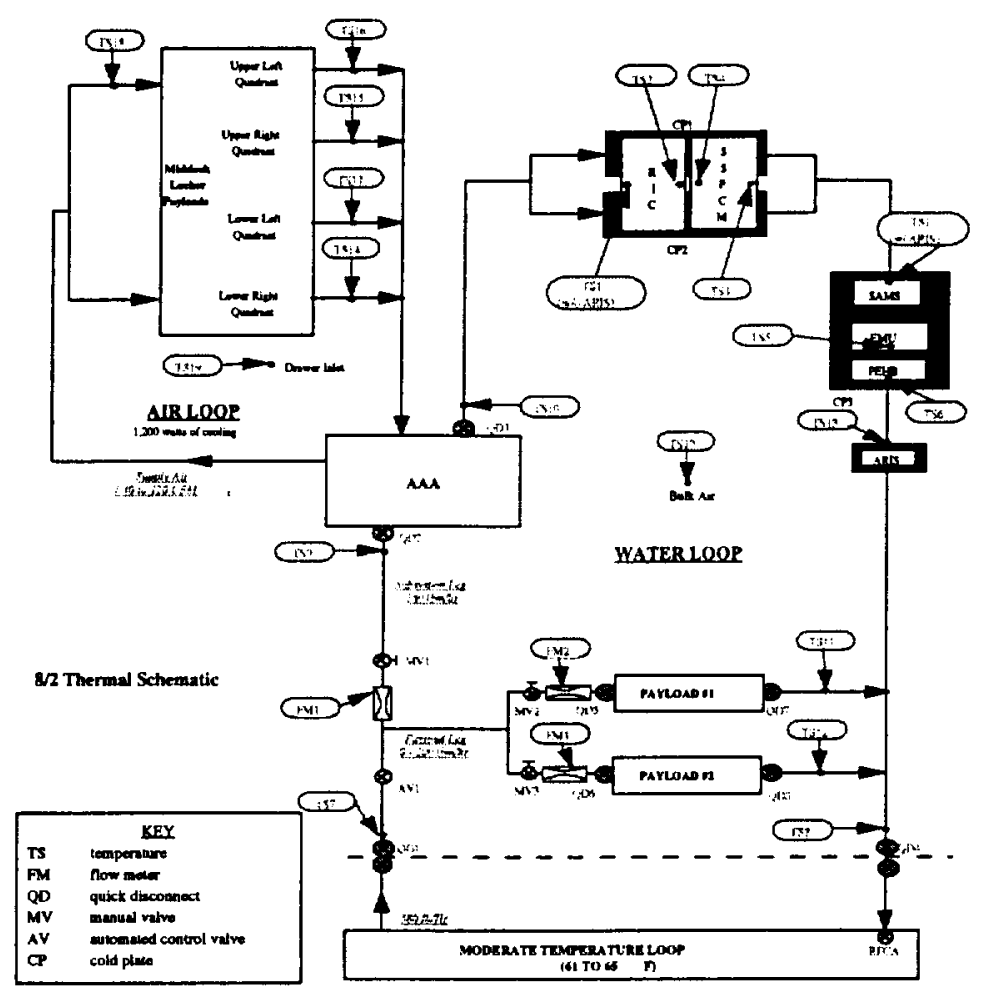

Figure 4b. Thermal Schematic

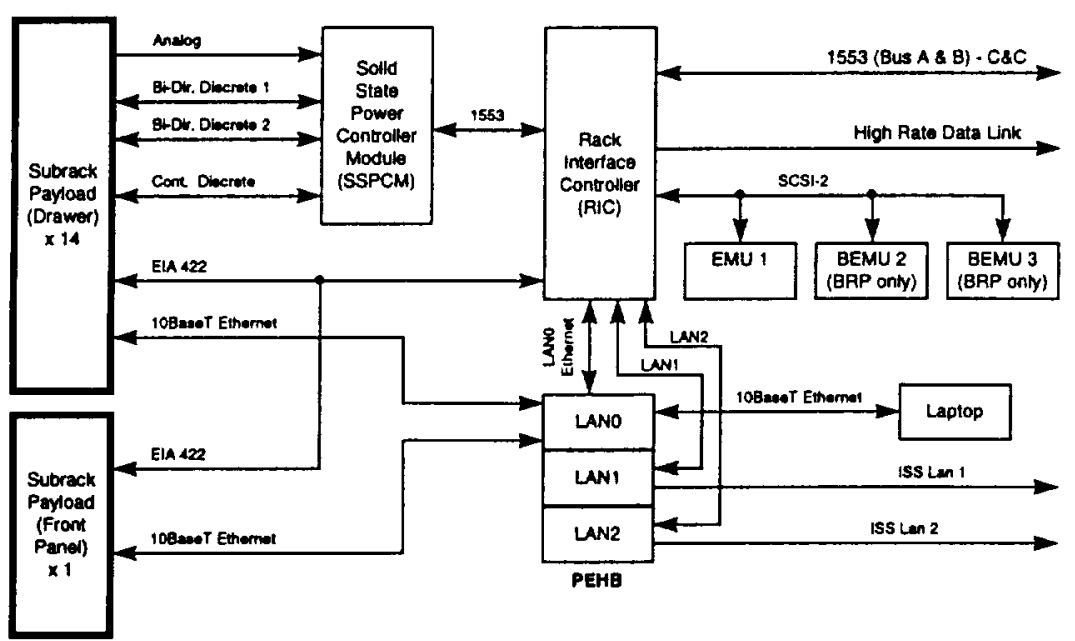

Figure 5. C\&DH Subsystem Schematic (for subrack payloads)

The avionics system also provides two (Dwr) or three (MDL) bi-directional 0 VDC to +5.0 VDC balanced/differential discrete interfaces, one (Dwr) or two (MDL) differential analog input signals at -5.0 VDC to +5.0 VDC with 10 bit resolution, $+/-1 \%$ full scale accuracy, one differential video interface, and one continuity discrete interface (Dwr only). Drawer payloads are required to short across two continuity pins upon drawer mate. 


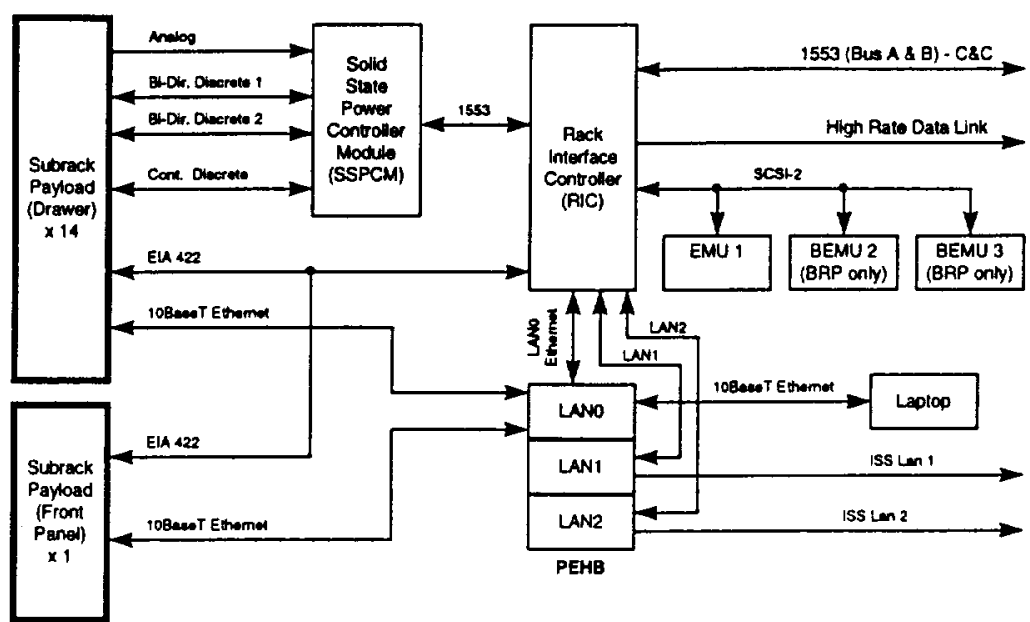

Figure 6. Video Subsystem Schematic (to Payloads)

The video subsystem is denoted in Figure 6.

Operationally, the C\&DH subsystem provides for payload commanding via the laptop and the ISS 1553 interface and uses either an Ethernet or EIA 422 interface for a given payload. Analog and discrete data is transmitted for downlink as part of rack health and status. Discrete output levels to payloads are commandable. Payload Ethernet data can be transmitted to the RIC for downlink and/or storage, directly to LAN1 or LAN2 if bridge enabled, to another Ethernet payload (directly through PEHB or to LAN0), or to a EIA 422 payload (via the RIC). EIA 422 data can be transmitted to the RIC for downlink and/or storage, to an Ethernet payload (via the RIC), or to another EIA 422 payload (via the RIC). A payload can use only one of the two interfaces (Ethernet or EIA 422) while operating.

The physical power and data interfaces are denoted in Figures $7-10$.

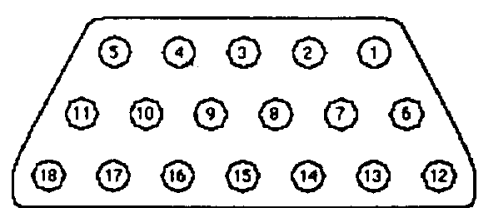

- Seal plugs are required in locations where contacts on either side of the connector are not used.

- Contact locations designated as "Reserved" are reserved for possible future use by various agencies, and these connections cannot be used without their permission.

- Contact locations designated as "Not Connected" are potentially available for use by the subrack payloads.

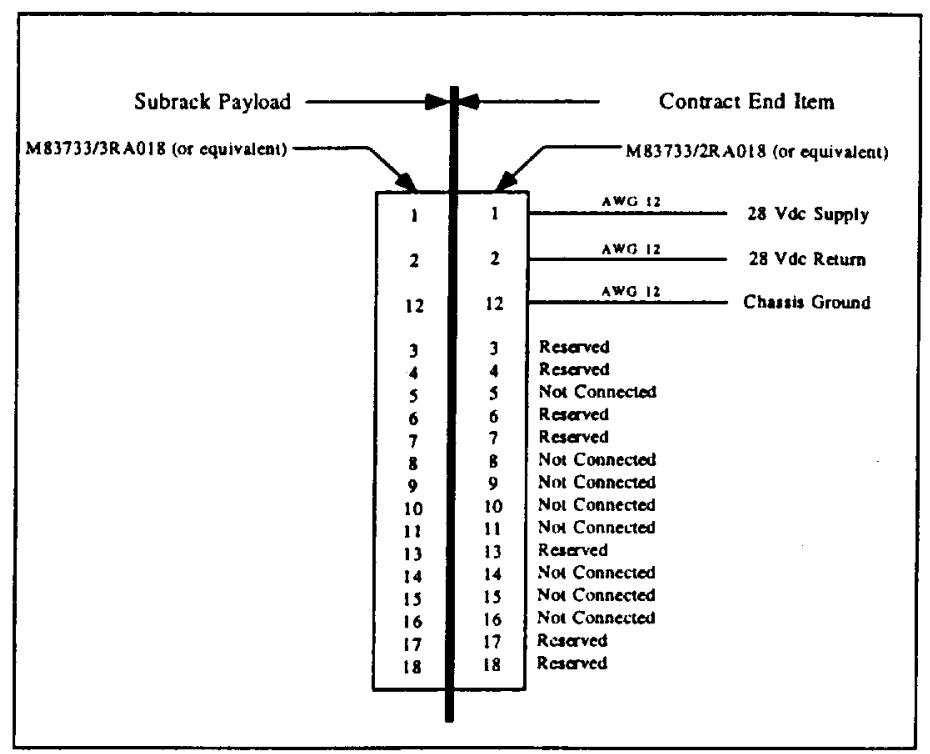

Figure 7. Power Connector Pin-Out (Drawer) 


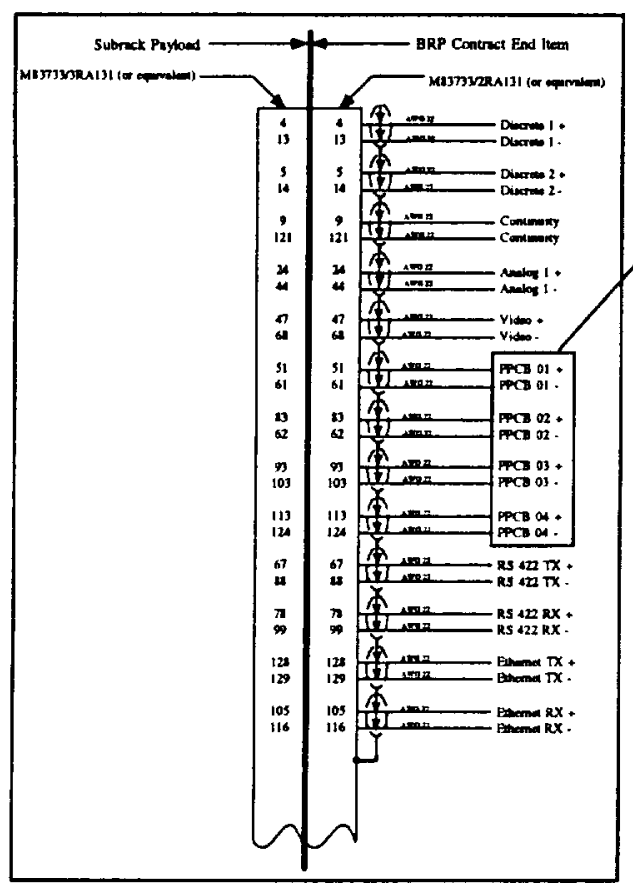

HRF only.

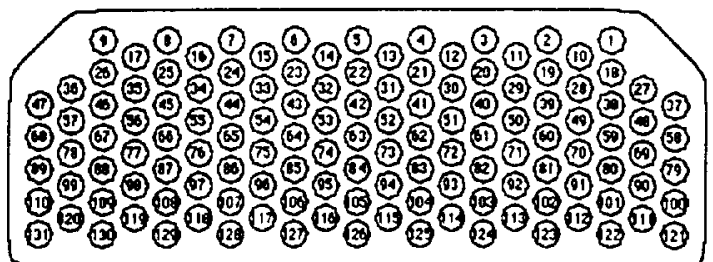

Figure 8. Data Connector Pin-Out (Drawer)

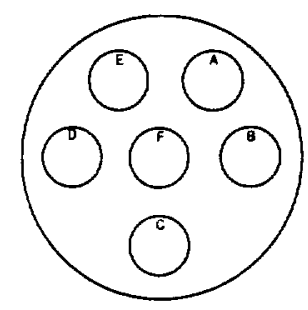

- Seal plugs are required in locations where contacts on either side of the connector are not used.

- Contact locations designated as "Reserved" are reserved for possible future use by various agencies, and these connections cannot be used without their permission.

- Contact locations designated as "Not Connected" are potentially available for use by the subrack payloads.

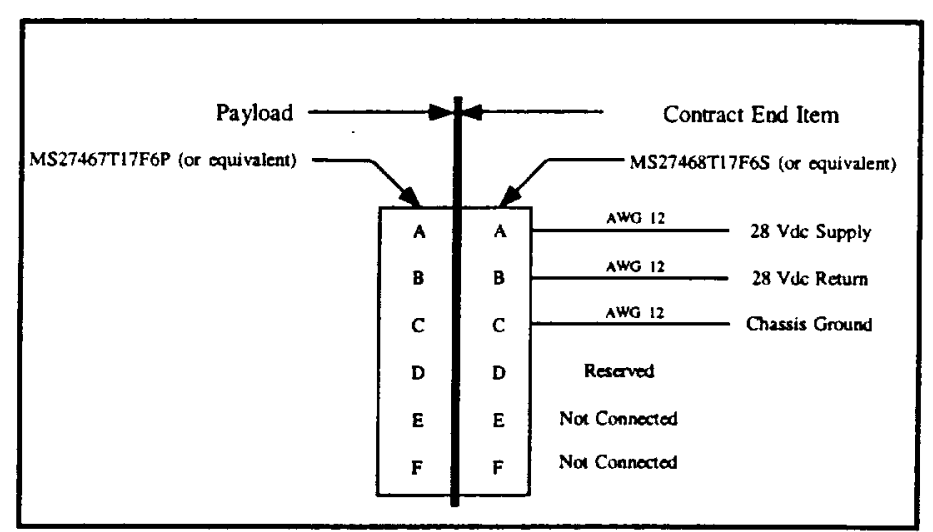

Figure 9. Power Connector Pin-Out (Mid Deck Locker) 


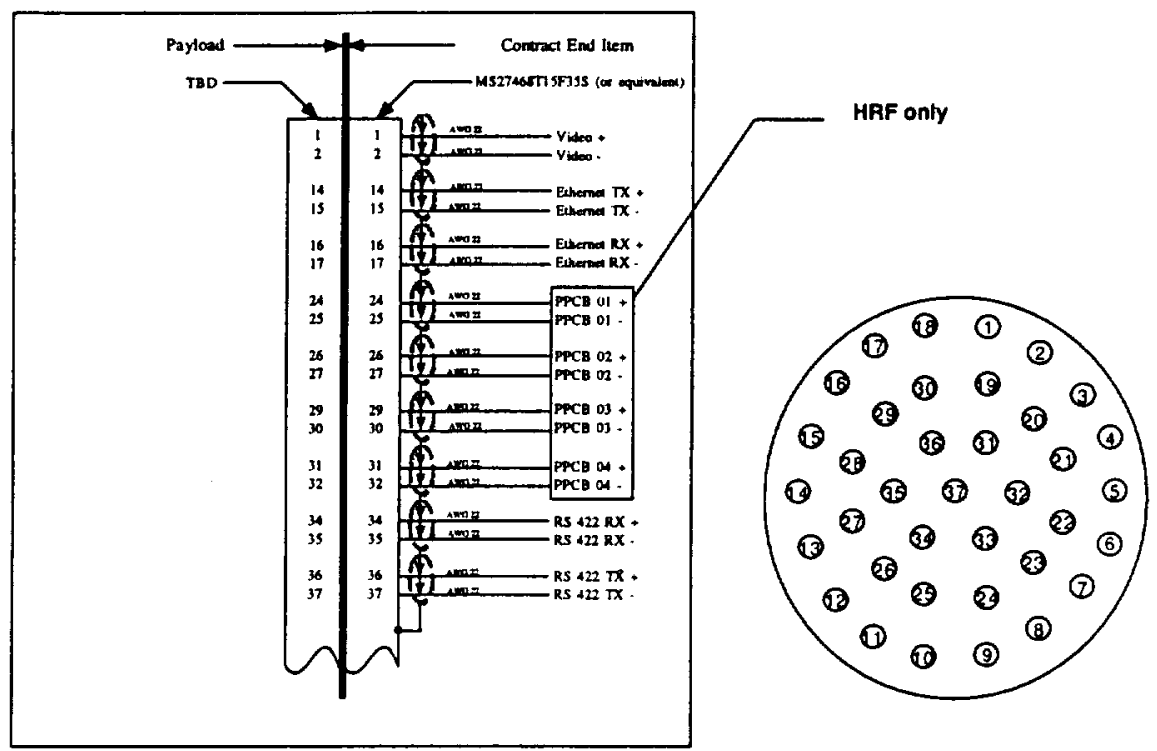

Figure 10. Data Connector Pin-Out (Mid Deck Locker)

The EXPRESS Rack provides access to the ISS Vacuum Exhaust System (VES) with hardware that will withstand a maximum interface pressure of 40 psia. The rack accepts the waste gases at a front-face connector panel. The acceptable gases are nitrogen, cabin air, noble gases, carbon dioxide, carbon monoxide (not more than $0.08 \%$ by volume), oxygen (not more than $30 \%$ by volume), hydrogen (not to exceed 25\% of the Lower Explosive Limit), methane (not to exceed 25\% of the Lower Explosive Limit), sulfur hexafluoride, and mixtures of these gases (not to exceed 25\% of the Lower Explosive Limit).

The EXPRESS Rack accepts gaseous nitrogen $\left(\mathrm{GN}_{2}\right)$ from the ISS at pressure between 75 to 120 psia (517 to $827 \mathrm{kPa}$ ). The EXPRESS rack does not limit the flow of $\mathrm{GN}_{2}$ to the using payload.

\section{PART II: POWER TECHNOLOGY- THE SSPCM}

\section{System Design}

The Solid State Power Controller Module (SSPCM) designed for the International Space Station (ISS) EXPRESS Rack is a remote-controlled power switching unit with both $120 \mathrm{~V}$ dc and $28 \mathrm{~V}$ dc Solid State Power Controllers (SSPCs). The SSPCs distribute and protect power to the various loads within the EXPRESS Rack. The SSPCM is designed with two $120 \mathrm{~V}$ dc inputs (Main and Auxiliary) and includes three $1100 \mathrm{~W}$ DC/DC converters to provide the payload $28 \mathrm{~V}$ dc. The Main $120 \mathrm{~V}$ dc bus normally provides the $120 \mathrm{~V} \mathrm{dc}$ for the payloads and the DC/DC converters. In the event of an undervoltage condition on the Main $120 \mathrm{~V} \mathrm{dc}$ bus, the SSPCM automatically switches the payloads and the DC/DC Converters to the Auxiliary $120 \mathrm{~V}$ dc bus. The SSPCM can be configured on orbit to control which payloads are powered during Auxiliary $120 \mathrm{~V}$ dc operations. This allows an experiment system to run without crew actions during numerous mission profiles. The SSPCM also provides payload analog and discrete inputs/outputs for experiment use. The SSPCM provides sampling rates up to $1 \mathrm{khz}$ and data formatting for payload data.

Two additional configurations consisting of more power channels and less payload analog and discrete inputs/outputs are also under development for the International Space Station Furnace Facility

The block diagram of the EXPRESS Rack SSPCM is shown in Figure 11. The SSPCM has redundant 1553/Master Modules for fault tolerant SSPC control. From dual $120 \mathrm{Vdc}$ inputs the SSPCM provides payloads $120 \mathrm{~V} \mathrm{dc}$ and $28 \mathrm{~V} \mathrm{dc}$ (via high efficiency DC-DC converters). 


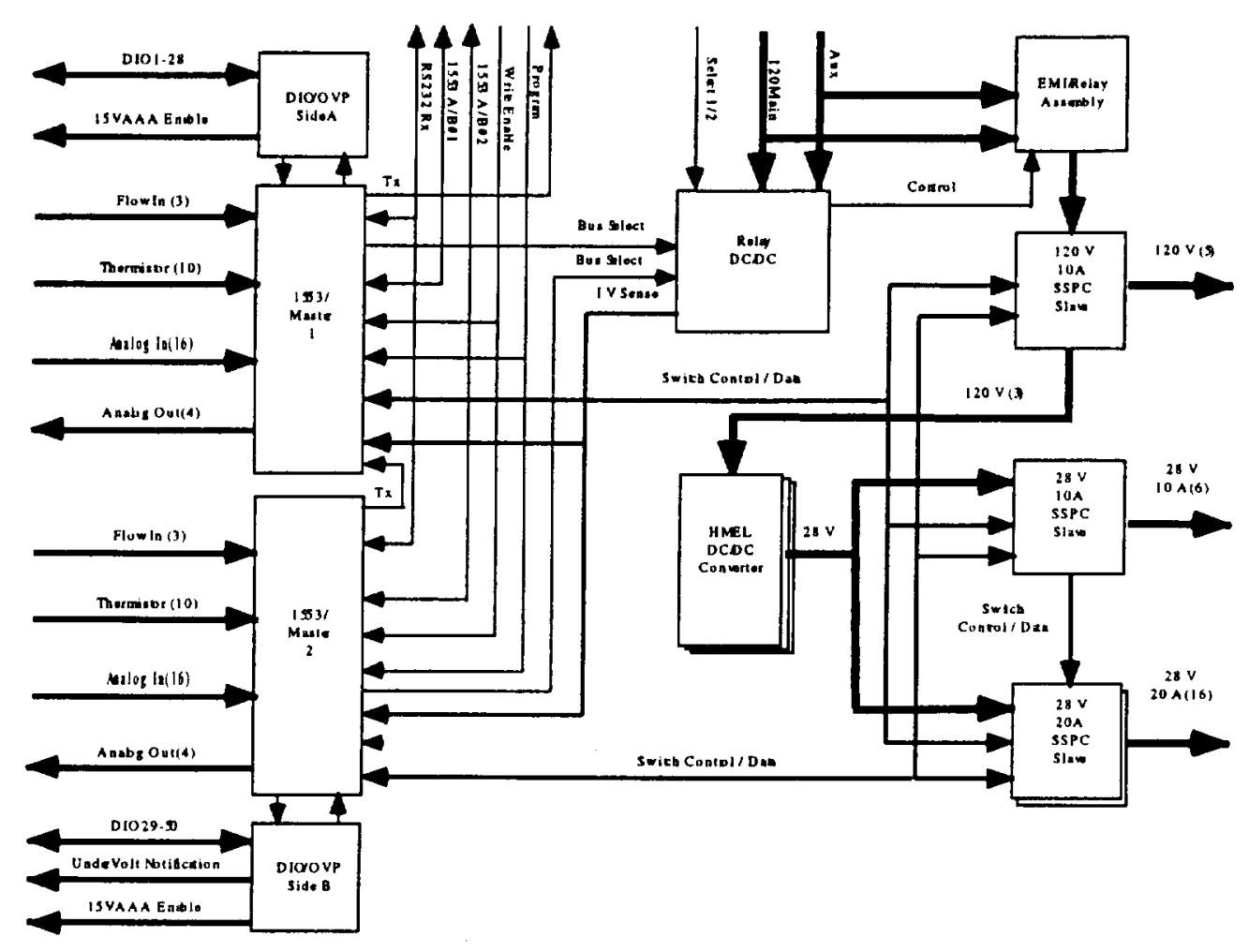

Figure 11. EXPRESS Rack SSPCM Block Diagram

\section{Hardware Design}

The SSPCM design consists of five module types: the 1553/Master Control module with payload VO (Inpu/Output), Discrete Input Output module with Overvoltage Protection, Relay Driver/DC-DC module, Slave Power Switch module, and the DC-DC Converter module.

\section{3/Master Module}

Each SSPCM unit uses two (redundant) 1553/Master Control modules with the payload I/O functions split between the two modules. The payload I/O functions are included in the 1553/Master modules to maximize payload acquisition rates. This has resulted in a high sampling rate $(1 \mathrm{kHz})$, a simple design, and low power consumption. Each 1553/Master control module provides ten thermistor inputs, three Flow Meter (4 to 20 $\mathrm{mA}$ ) inputs, sixteen $+/-5 \mathrm{~V}$ differential analog inputs and four $+/-5 \mathrm{~V}$ complimentary 8 bit resolution analog outputs. Overvoltage protection of $+/-30 \mathrm{~V}$ is provided on all $\mathrm{VO}$ lines. The 1553 Master module uses 12 bit AD conversion for all analog inputs. The United Technologies UTMC UT69RH051 is used for the processor. It features high radiation tolerance, on board RAM, programmable I/O lines, programmable UART, low power consumption, and an industry standard 8051 instruction set.

Two EEPROMs are provided on each 1553/Master controller module. One EEPROM is used for the program (software) memory and the other for the nonvolatile storage. The SSPCM can be configured (stored in nonvolatile RAM) to power any SSPC output at power up to ensure critical payloads are operational as soon as possible. The SSPCM can also be configured to ensure certain payload channels receive power during critical phases such as reduced rack power operations and power bus failures. This feature can be very important to Life Science Experiments. 
The 1553/Master module controls the SSPC operation on the slave modules via high speed serial optically isolated interfaces. This method allows each power bus to remain isolated. The high speed serial interfaces also provide verification of command patterns prior to execution of on/off commands and current rating changes of the SSPCs. Current and voltage analog status from the SSPCs are received by each 1553/Master Module via differential amplifiers with 2 mega-ohm isolation. Either 1553/Master module can be configured as the "active" controller and control all of the SSPCs.

\section{Discrete Input Output / Overvoltage Protection (DIO/OVP) Module}

The SSPCM uses one DIO/OVP Module to provide payload discretes and I/O overvoltage protection. The DIO/OVP provides 112 single ended or 56 differential bi-direction inputs/outputs. When configured as inputs they are sampled at a $1 \mathrm{kHz}$ rate. As outputs they are under control via MIL-STD-1553 or RS232 data ports.

\section{Relay Driver Module/DC-DC}

The SSPCM uses one Relay Driver Module (RDM). The function of the RDM is to provide drive for the electromechanical latching main bus relays and to provide internal redundant power to the Slaves, 1553/Master, and DIO/OVP modules.

Main and Aux powers are monitored by hardware to switch internal power in the event of any dropouts below 80V. An on-board relay is used to switch from Main to Aux to insure SSPCM internal power integrity during these dropouts. The main bus relays are mounted on the SSPCM housing. The main power bus is monitored for voltage dropouts greater than 5 milliseconds. A voltage dropout of longer than 5 milliseconds causes the unit power to be switched to the Aux bus along with the required loads. The RDM also provides the main bus current and voltage sensor circuitry.

The RDM also contains system redundant power supplies and SSPC Master control selection interface. This interface allows selection of either of the two 1553/Master modules by the external controller for the control of the SSPCs.

\section{Slave (Power Switch) Module}

Each SSPCM can contain between 4 to 9 Slave Modules for EXPRESS Rack and different Furnace Facility configurations. The Slave Module uses redundant serial shift registers for control of the power switches. The sequences of shift register patterns are verified via software prior to command transfer to the SSPCs. This procedure prevents transfer of erroneous commands from the Master Module. The Slave Module also provides multiplexed transfer of analog data to the Master Modules.

Each Slave Module consists of eight McDonnell Douglas Proprietary SSPCs. Currently there are three different types of SSPCs: $120 \mathrm{~V} \mathrm{10A,} \mathrm{28V} \mathrm{10A,} \mathrm{and} \mathrm{28V} \mathrm{20A.} \mathrm{The} \mathrm{SSPCs} \mathrm{in} \mathrm{the} \mathrm{Slave} \mathrm{Module} \mathrm{contain} \mathrm{the}$ power switching components, current limit, and trip timing circuits, and the output voltage and current signal circuits. International Rectifier $400 \mathrm{~V}$ and $60 \mathrm{~V}$ (for the $120 \mathrm{~V}$ and $28 \mathrm{~V}$ SSPCs, respectively) MOSFETs with proven radiation data were used. Three of these N-channel MOSFETs were placed in parallel to minimize power loss. The current design uses discrete surface mounted circuitry but future plans call for hybridizing the SSPC for applications requiring a smaller footprint.

The SSPCs can be programmed for four different trip levels. There is a fast current limit independent of the trip setting. The current limit circuit utilizes a current sense resistor in the source of the MOSFETs. A bipolar transistor senses the voltage across the resister and pulls down on the gate of the MOSFETs during current limit. The transistor is biased such that the current sense resistor can be very small for low loss. The short circuit current limit is on the order of $200 \%$ of the breaker's maximum rating. From this level, the $\mathrm{I}^{2} \mathrm{t}$ trip curve blends smoothly into the trip current setting. The boundary of this provides for charging a load capacitance of a given value while protecting the MOSFETs. Circuitry extends the trip time if the output 
voltage rises (the signature of a constant current charging a capacitance). In the event of a trip, the SSPC is latched off and the only way to turn it back on is to bring its on/off control line low then back high. This ensures that a tripped SSPC cannot be turn on accidentally.

The "On" to "Off" and "Off" to "On" transition of the MOSFET power switches have a time constant associated with them. This reduces line surges during these periods.

The SSPC has a clamp transistor to keep Vout low when the switch is off. The clamp transistor is a pchannel MOSFET complementary to the n-channel MOSFETs. Due to the back to back connections between the transistors, the switch and the clamp cannot be on simultaneously with consequent damage.

\section{$D C-D C$ Converter}

The SSPCM provides up to 2200 Watts of $28 \mathrm{~V}$ dc power via DC-DC converters internal to the SSPCM. The DC-DC converter is composed of three $1100 \mathrm{~W}$ elements that are mounted on modules within the SSPCM housing. All three elements operate in parallel and share power within $+1.5 \%$. In most failure modes, the SSPCM converters power capability would degrade gracefully in $1100 \mathrm{~W}$ increments. Each DC-DC converter features high efficiency $(90 \%+)$ coupled with light weight $(2.2 \mathrm{lbs})$ and small size $(<40$ in3). In order to minimize EMI filtering requirements, a zero ripple current topology was chosen, which utilizes flux steering techniques. The DC-DC converters were designed and fabricated by our teammate Hughes Microelectronics in Glenrothes, Scotland.

\section{Future SSPCM Development}

Future development plans for the SSPCM in addition to the EXPRESS Rack and Furnace Facility configurations include the hybridization of the SSPCs, development of a higher processing power Master Module, development of smaller "mini" units targeting distributed power systems (such as aircraft), and development of an AC SSPC

\section{Conclusions/Summary}

The Solid State Power Controller Module (SSPCM) designed for use in the International Space Station (ISS) EXPRESS Rack is a remote-controlled power switching module with $28 \mathrm{~V}$ dc and $120 \mathrm{~V}$ dc Solid State Power Controllers (SSPCs). The SSPCs distribute and protect power to various loads within the EXPRESS Rack. The SSPCM can also provide many of the required subsystem and payload data gathering and formatting functions. Highly efficient $(90 \%+)$, light weight DC-DC converter modules provide power for the $28 \mathrm{~V}$ loads.

\section{PART III: DATA STORAGE TECHNOLOGY- THE BEMU}

\section{Background}

The Habitat Holding Rack, as discussed previously, has a relatively large minimum data storage requirement of 5.06 Giga-bytes (GB). Originally, three units of an upgraded version of the EXPRESS Memory Unit, a 320MB device based on solid-state flash-memory storage cards, were envisioned to meet this need. Each upgraded unit was to have a capacity of $1.7 \mathrm{~GB}$. The device discussed in this paper, called the Biological Research Project EXPRESS Memory Unit, or BEMU for short, is a new development item based on Boeing-modified 9.1GB commercial disk-drives from Western Digital Corporation, Irvine, CA. Modifications to the drive are required to stake down all circuit board components and provide a conductive path for heat rejection. Three BEMUs will be installed in each HHR, providing a double-redundant capacity of $9.1 \mathrm{~GB}$, and for a total capacity of $27.3 \mathrm{~GB}$. The BEMU is intended to meet all the Habitat Holding Rack data storage requirements at reduced cost when compared to alternative solid state devices. 


\section{Design Requirements}

Three BEMU units, each of a minimum capacity of $5.06 \mathrm{~GB}$, are to be installed in each HHR. (Multiple units allow data storage redundancy and higher system reliability.) Each BEMU must have a mean time between failure of at least 60,000 hours. The BEMUs must communicate with the rack controller via the narrow-SCSI data protocol, operate on 28 volts DC, and be conduction-cooled. Approximately $20 \mathrm{~W}$ of power have been allocated for each BEMU. The BEMU is not required to be hard-mounted in the rack during launch, but may be transported to orbit in foam-packed storage. (Mounting in the rack is desirable, however, to reduce stowage requirements and on-orbit rack setup time. Random vibration tests have been conducted to determine the ability of the device to withstand launch vibrations.)

While no vibration emittance requirement is specified, it is highly desirable that the BEMU not emit significant vibrations below $100 \mathrm{~Hz}$. Disk-drives operating at $7200 \mathrm{RPM}$ were preferred, therefore.

Finally, the BEMU is an electrical device in the rack which must be replaceable by the crew. Therefore, it must meet a host of requirements common to all such hardware such as rounded edges, captive fasteners, electrical bonding and grounding, electromagnetic interference, toxic off-gassing limitations, etc.

\section{Device Description}

An exploded view of the BEMU is shown in Figure 12. The BEMU consists of an un-vented aluminum enclosure, a Boeing-modified commercial disk drive, a radiation hardened power supply from Lambda Advanced Analog, a matched EMI filter on the input power line (also from Lambda), separate MIL-C38999 Series II power and data connectors, and an internal wiring harness.

The enclosure consists of a base and lid separated by an EMI gasket. Captive fasteners are employed for mounting. Internally, the disk-drive is mounted to the base, while the EMI filter and power supply modules are mounted to the lid.

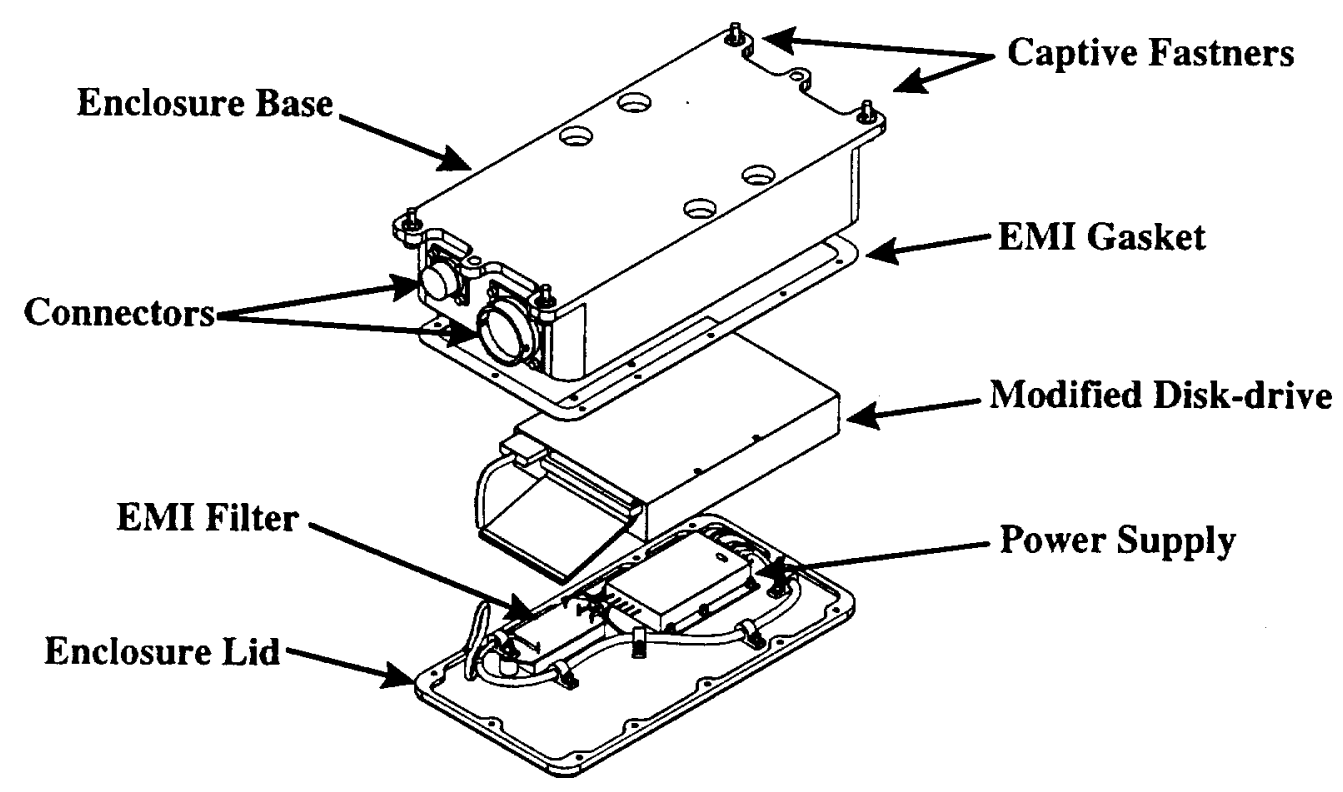

FIGURE 12. Exploded View of the BEMU 
The disk-drive chosen is an "Enterprise" model from Western Digital with 9.1GB of formatted capacity. This drive is modified in-house using a Boeing-developed process. This process, as shown in Figure 13, applies a layer of thermally conductive, but electrically resistive, rubber (Chomerics Therm-A-Form 644) to both sides of the circuit board. The rubber is supplied as two liquid compounds which are mixed during application and then cure in place. This provides complete encapsulation of the circuit board components and allows heat from the board and drive motor to be conducted to the enclosure base. Tooling is used to form a flat surface on the rubber which is slightly above the normal mounting plane of the drive. When the drive is installed into the enclosure the rubber becomes slightly compressed, which is required for optimum thermal transmission.

\section{Developmental Test Results}

Developmental tests have been carried out on three units, each identical except for the make of disk-drive employed. Models from Seagate, Quantum and Western Digital were tested as shown in Figure 14. The Western Digital was chosen for the flight units, based primarily on superior thermal and radiation test performance. The results presented are for the Western Digital-based unit only.

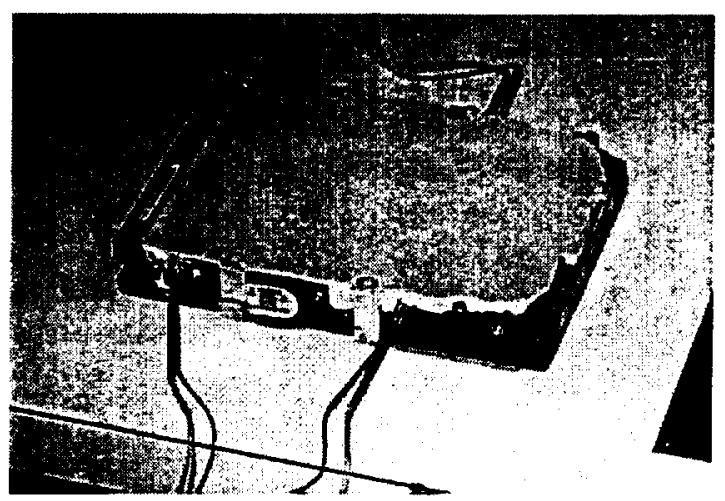

FIGURE 13. Modified Disk-drive

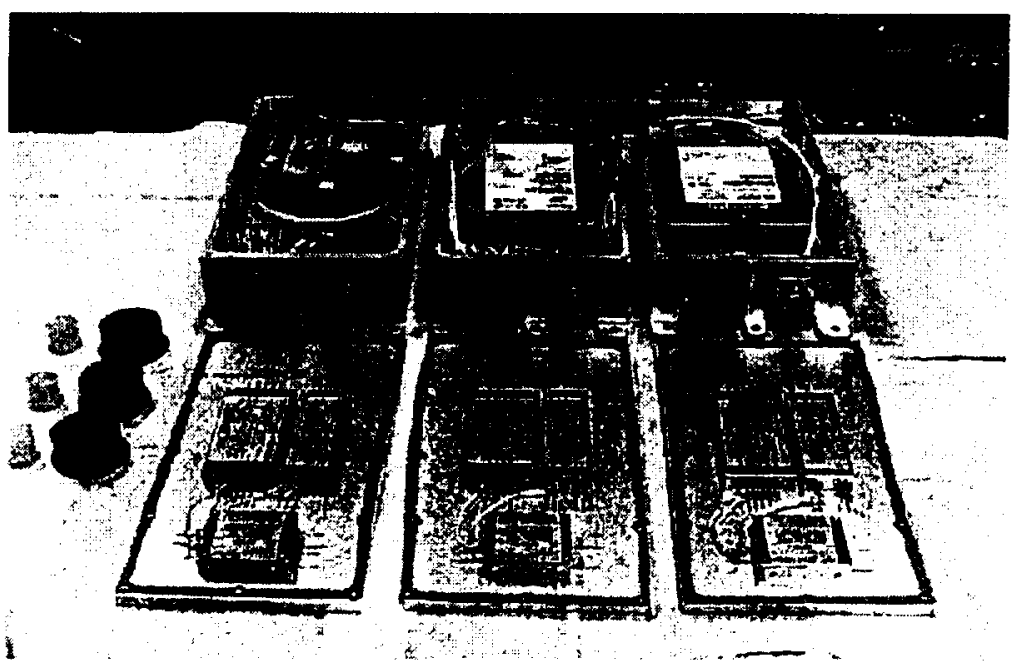

FIGURE 14. BEMU Developmental Test Units 
Toxic Off-gassing The developmental unit was subjected to toxic off-gas testing per NHB 8060.1C, Test 7 at Marshall Space Flight Center. It received an "A" rating. Summation of "T" was 2.1E-05, which is well below the NASA-established limit of 0.5 .

Thermal Testing The developmental unit was thermally tested during operation in a continuous read/write mode while the base of the enclosure was maintained at $45^{\circ} \mathrm{C}$. This is the predicted worst-case environment in the Habitat Holding Rack. (The other faces of the enclosure were insulated.) The unit consumed $17.1 \mathrm{~W}$ during continuous disk accessing. Temperature results for both the drive case temperature and the worstcase micro-chip temperature are shown in Table 1. The margin of $4^{\circ} \mathrm{C}$ on the case indicates that the units can be qualified for operation at a baseplate temperature of $49^{\circ} \mathrm{C}$ and still maintain Western Digital's reliability specification of one million hours for mean time between random failure. Operation at higher temperatures is possible, but may entail some loss of reliability.

TABLE 1. Thermal Test Results

\begin{tabular}{|r|c|c|c|}
\cline { 2 - 4 } \multicolumn{1}{c|}{} & $\begin{array}{c}\text { Operating } \\
\text { Temp, C }\end{array}$ & $\begin{array}{c}\text { Reliability Maximum } \\
\text { Temp, C }\end{array}$ & $\begin{array}{c}\text { Margin } \\
\text { C }\end{array}$ \\
\hline Micro-chip & 48 & 65 & 17 \\
\hline Case & 51 & 55 & 4 \\
\hline
\end{tabular}

Radiation Testing Heavy ion beam, single event radiation effects testing was carried out on two disk drives at the National Superconducting Cyclotron at Michigan State University in East Lansing. Each component was irradiated individually with varying beam intensities, as shown in Figure 15. Both functional interrupts and component failures were observed. Functional interrupts cause no permanent damage and are cleared by recycling power to the unit. Based on these test results, the rates of occurrence for these effects in Space Station orbit for a single drive are estimated at 300 days for functional interrupt and 5000 days for failure.

Vibration Emittance Testing Measurements of the vibration emitted by the BEMU during operation were taken. The developmental unit was suspended, as shown in Figure 16, by a bungee cord, allowing the unit to swing and rotate freely. The suspension was to exhibit less than a $1 \mathrm{~Hz}$ natural frequency in the directions of interest to assure good test results above $10 \mathrm{~Hz}$. Care was taken to arrange power and data lines so as to not impede the units' freedom of motion. As suspended, the pendulum mode was $0.4 \mathrm{~Hz}$, the spin mode was $0.2 \mathrm{~Hz}$. Model 393B12 seismic-type accelerometers from the PCB recorded vibration during three modes: 1) start up, 2) idling, and 3) accessing the disk.

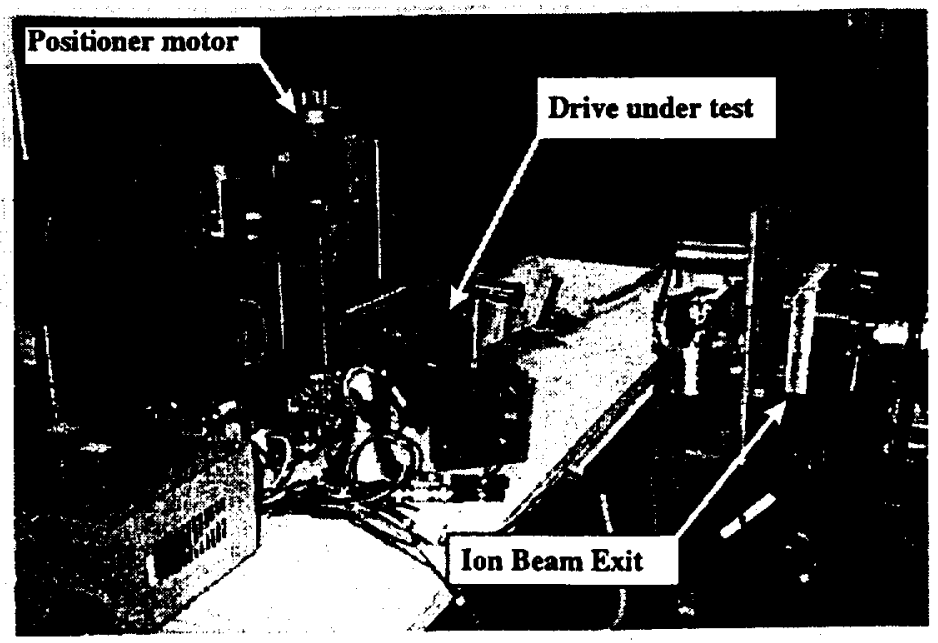

FIGURE 15. Single Event Radiation Test 


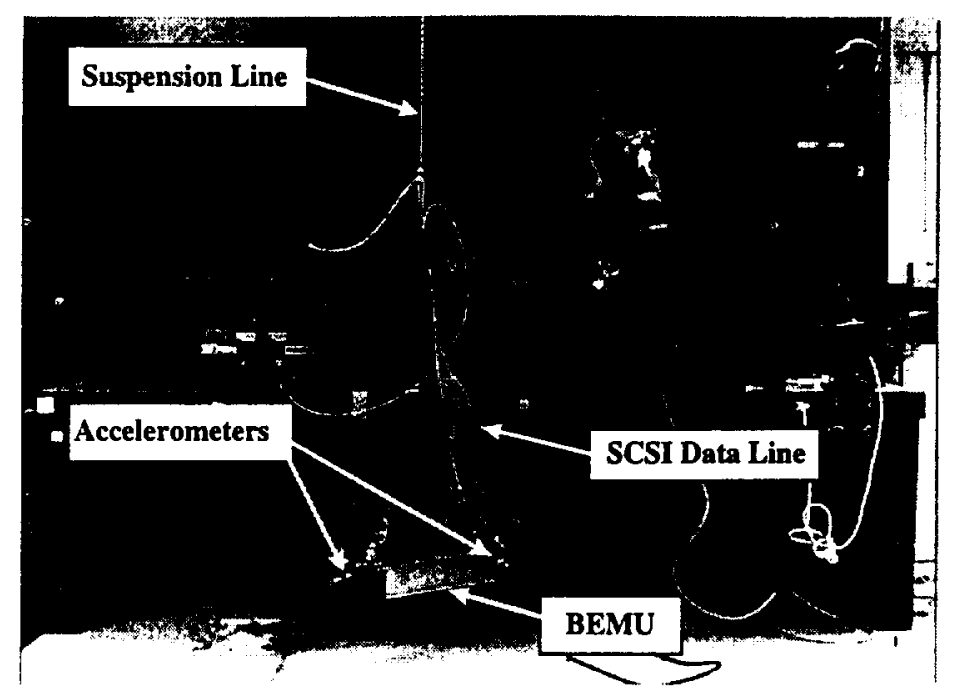

FIGURE 16. Vibration Emittance Testing of BEMU

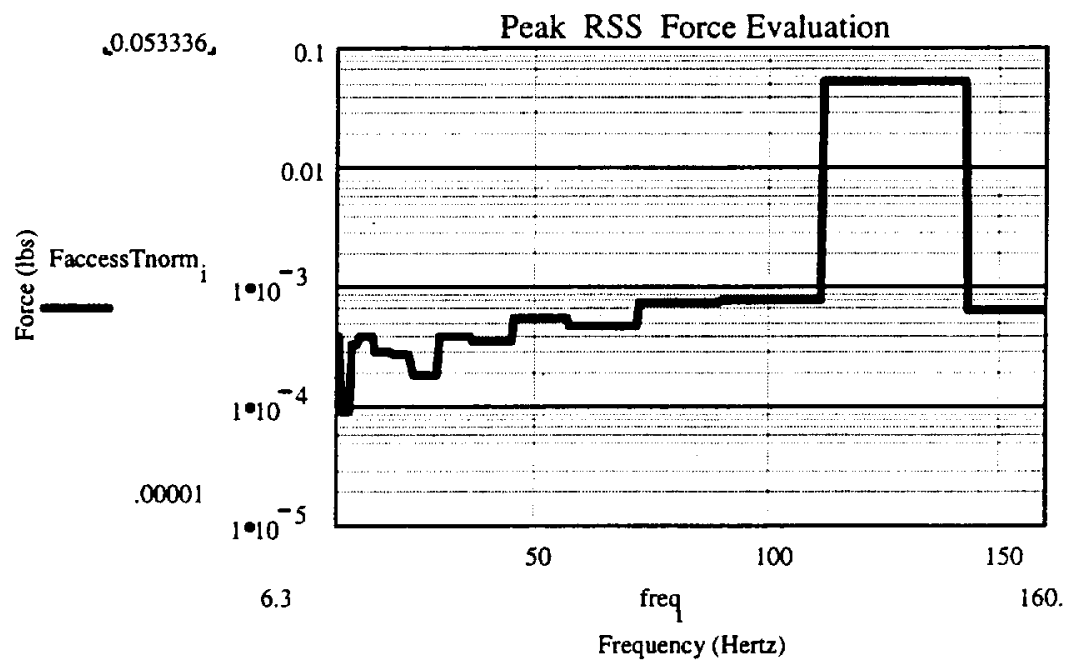

FIGURE 17. Vibration Emittance Test Results

Results for vibration emitted during disk accessing (reading \& writing) operations are shown in Figure 17. Results are reported as normalized, $1 / 3$ Octave band, root-sum-square peaks from $\mathrm{OHz}$ to $160 \mathrm{~Hz}$. The only significant vibration results from platter imbalance at its rotational speed of $120 \mathrm{~Hz}$ and is in agreement with the manufacturers' balance specification.

Random Vibration Testing Random vibration testing (non-operating) was performed on the developmental unit to determine its ability to withstand launch vibrations. Two of three axes have been tested, with the third axis test pending. The unit operated normally after testing in the first two axes. The test level was 1.5 times the design level of $4.4 \mathrm{grms}$. Test tolerances were plus $3 \mathrm{db}$ and minus $1.5 \mathrm{~dB}$

\section{Conclusions \& Future Plans}

Developmental testing of the Western Digital-based prototype BEMU has shown that it can meet all design requirements, including thermal and radiation environmental stresses. Vibration emittance testing has shown that the BEMU will not be a significant vibration disturbance at frequencies below $100 \mathrm{~Hz}$. Qualification testing is scheduled to occur between May and July of 1999. The first flight units are 
scheduled for delivery in September of 1999 for installation into the Habitat Holding Rack qualification test article.

\section{PART IV: MICROGRAVITY TECHNOLOGY- THE PASSIVE DAMPING SYSTEM}

\section{Background}

A trade study and preliminary design have been developed to determine the feasibility of isolating International Space Station (ISS) payload racks from the ambient vibration environment through passive means. The resultant system is called the Passive Damping System (PDS). The trade study was performed in three phases and was completed in September of 1997. Currently, the PDS is required for the Habitat Holding Rack (HHR), an EXPRESS rack derivative being designed by Boeing for the Biological Research Project and managed by NASA-Ames Research Center, Moffett Field, CA. However, the preliminary PDS design allows for implementation in any International Standard Payload Rack (ISPR)-based payload rack, within the confines of the existing United States Laboratory (USL) module-to-ISPR structural interface (See Figure 18). The first PDS is scheduled to be flown to the ISS on Space Shuttle flight STS-117 (ISS flight UF-3), along with the first HHR to be installed in the USL module.

Work performed to date has included: establishing isolation performance requirements, calculating isolation performance based on parametric studies of spring and damping combinations, determining feasibility of existing spring and damper technologies for PDS, defining existing ISS module-to-HHR interfaces, and development of PDS packaging concepts within the ISS-to-HHR structural interface. Developmental testing has also been performed to determine micro-gravity level isolation performance for test units having damping and stiffness properties similar to those needed for the PDS. Additional component and system level testing is planned for the detail design phase of the PDS program.

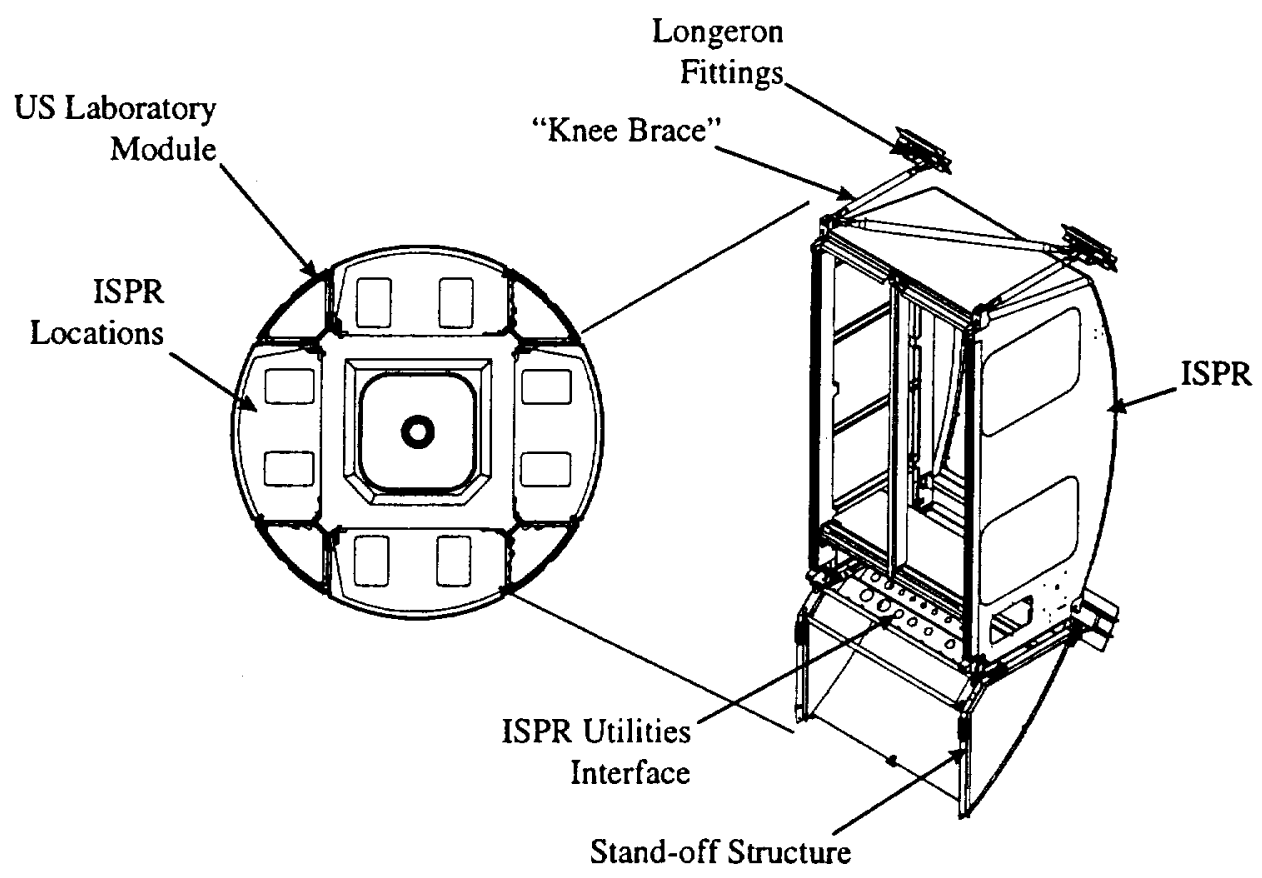

FIGURE 18. Section view of U. S. Laboratory module showing isometric view of ISPR mounted in USL secondary structure. 


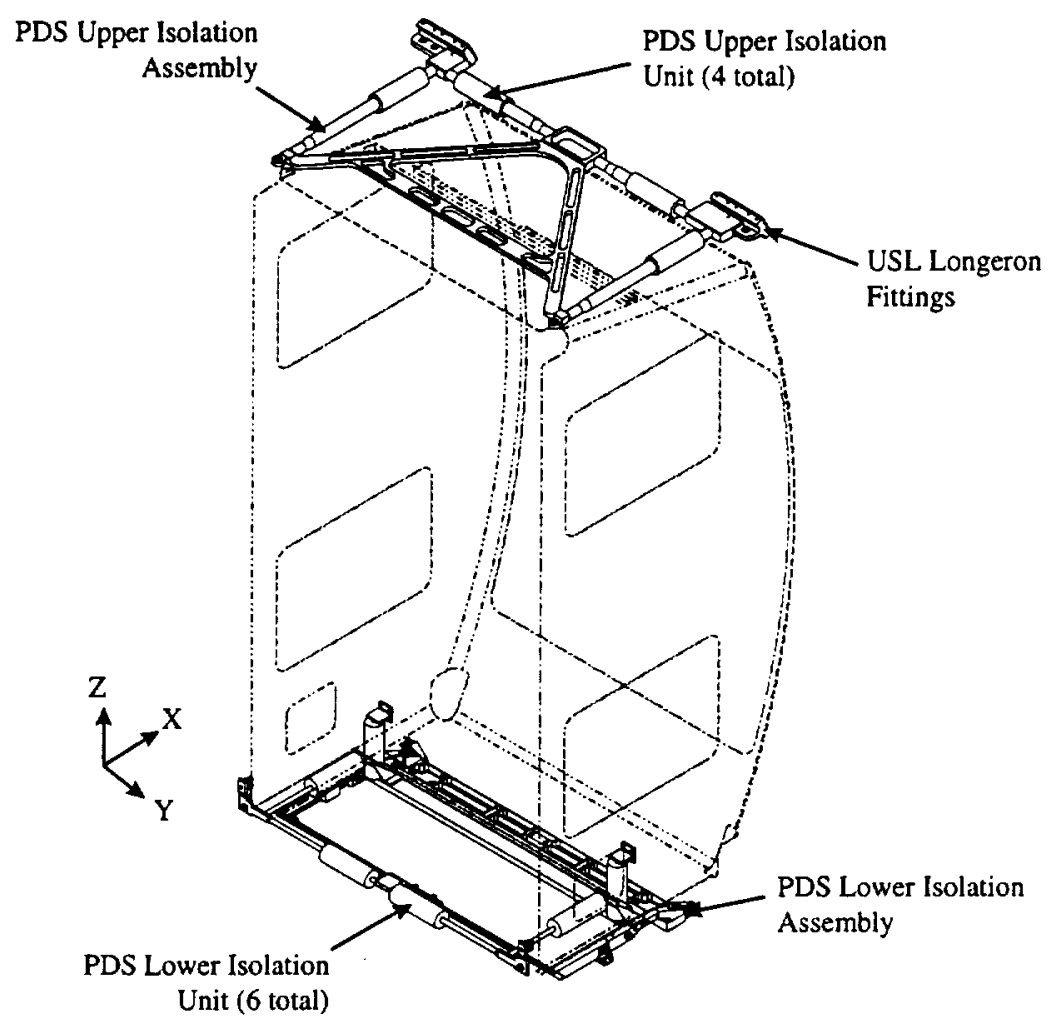

FIGURE 19. Illustration of PDS showing upper and lower isolation assemblies. Isolation units are oriented along each X-, Y-, and Z- global axis and are murually orthogonal. USL structure is removed for visual clarity.

\section{System Hardware}

The preliminary PDS design developed during the trade study has two major assemblies: the upper isolation assembly and the lower isolation assembly. Both isolation assemblies are illustrated in Figure 19. The upper isolation assembly is mounted between the upper-front ISPR fittings and two USL longeron fittings.

The USL longeron fittings shown are attach points for the "knee brace" assembly that normally provides the rigid connection between the ISPR and the USL. The upper isolation assembly essentially replaces the "knee brace". The lower isolation assembly mounts between the USL stand-off structure and lower attach points located on the ISPR. All lower isolation assembly hardware must avoid the utility umbilicals both during static restraint and dynamic movement.

Once the ISPR is isolated from the ISS structural attach points, the umbilical assembly that delivers the needed utilities to the payloads still remains as a path for vibration to enter (or exit) the ISPR structure (See Figure 20). Much work has been done during development of the ISS Active Rack Isolation System (ARIS) in designing a utility umbilical assembly with low stiffness and bias force properties. However, there is no requirement for ARIS-configured payload racks to utilize low temperature water for liquid cooling. Use of this water requires that both supply and return plumbing be insulated to prevent condensation. Because the HHR uses ISS low temperature water, designs for an insulated, low stiffness low temperature water umbilical were developed. One such design, constructed of a metal bellows sheathed coiled water line, is illustrated in Figure 21. 


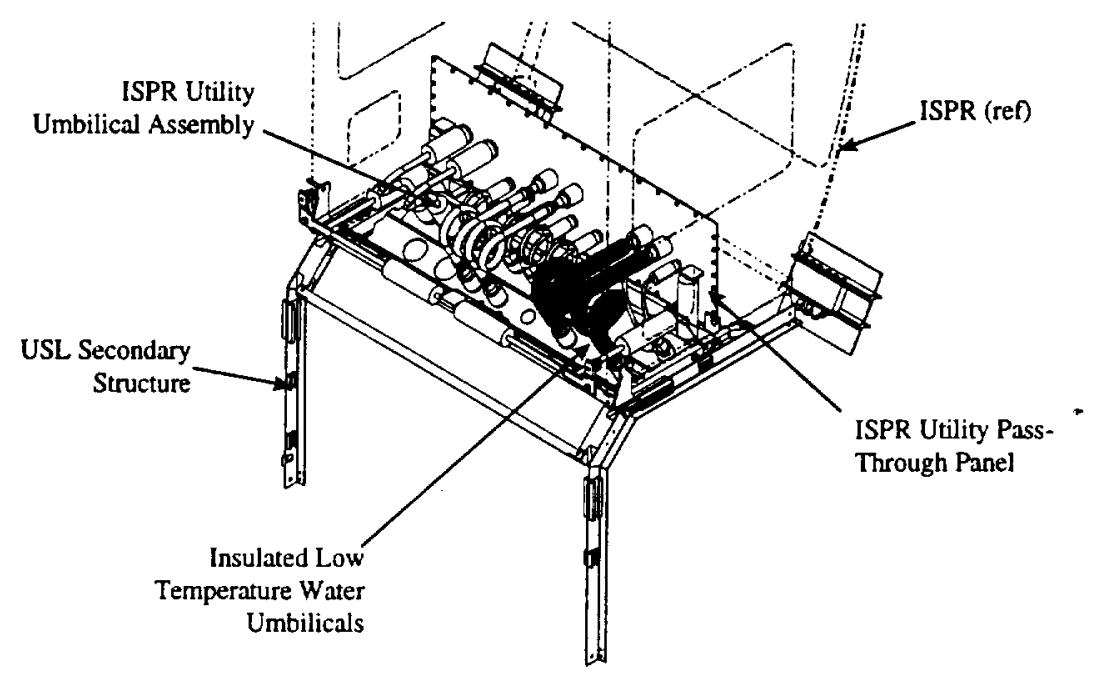

FIGURE 20. Illustration of PDS showing lower isolation assembly and USL structure with Rack utility umbilicals installed. Also shown is the low temperature water umbilicals. The coiled shape of the umbilicals greatly reduces static stiffness and bias force of the assembly.

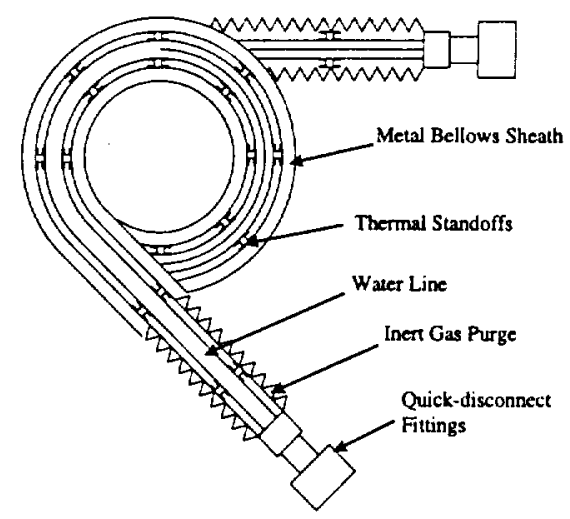

FIGURE 21. Detail of PDS insulated low temperature water line. An inert gas, such as Krypton, is used to purge the void between the water line and sheath for insulation. Thermal standoffs prevent the sheath from touching the water line and creating a thermal "short circuit".

Technologies considered for the PDS isolation units included: pneumatic and hydraulic fluid damping, constrained boundary damping, magnetic field damping, visco-elastic material damping, pneumatic springs, mechanical springs, and negative stiffness devices. The PDS trade study concluded with a recommendation for a device using pneumatic damping and a metal bellows for stiffness (See Figure 22). Advantages of this design are extremely low dynamic and static friction, a damping curve predicted to decrease with frequency, and no concerns relevant to fluid containment or leakage. Development test have shown that at low velocities, the pneumatic damper acts like a damper. At higher velocities, the pneumatic damper acts more like a spring, reducing transmissibility. 


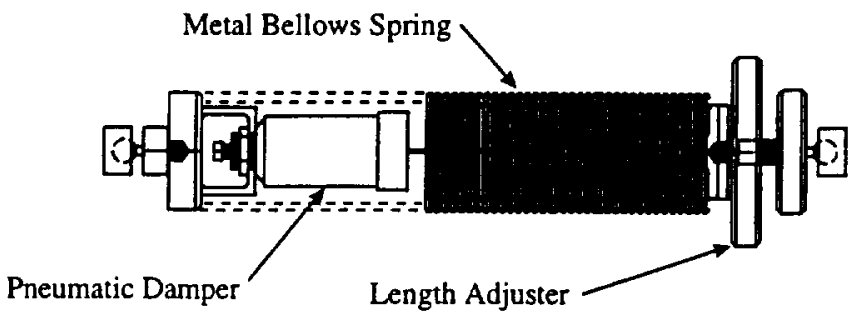

FIGURE 22. PDS pneumatic damper and metal bellows isolation unit. The metal bellows provides both stiffness and encasement of the damper. The length adjuster allows for adjustment of the isolated Rack's center of movement, by shortening or lengthening of the isolation struts.

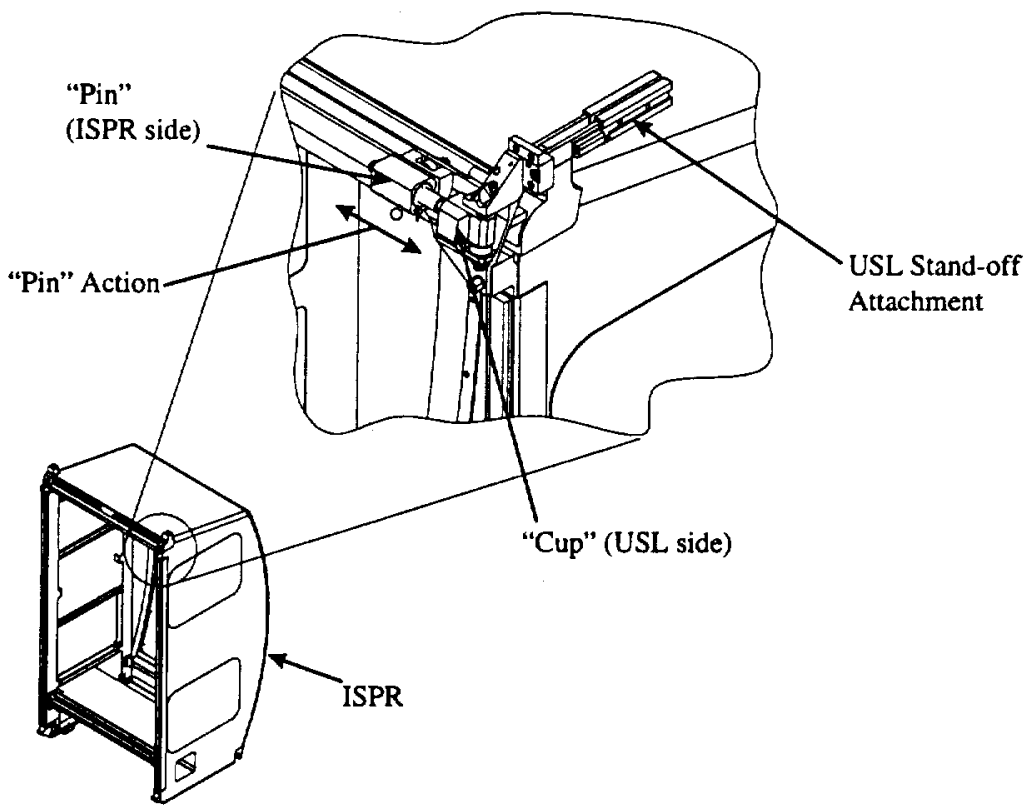

FIGURE 23. Illustration of PDS snubber/lock-down fitting (USL structure removed for clarity). Similar fittings are located at all front comers of ISPR.

Also incorporated into the PDS are mechanisms that lock-down the ISPR's movement during maintenance activities, as well as limit the rack's displacement within the dynamic envelope. Controlling the maximum displacement, or "snubbing" the movement, is needed to prevent collisions with adjacent payload racks and USL structure. As with the utility umbilical assembly, existing designs used for ARIS are planned to be reused for the PDS. These lock-down/snubbing devices are attached to the front upper and lower ISPR fittings, exposed to a crew member during on-orbit operations, and the USL secondary structure. This allows for ease of operation and maintenance. An illustration of the upper right, lock-down/snubbing fitting is presented in Figure 23. The "Pin" fully engages the "Cup" upon lock-down. The "Pin" is slightly retracted to provide sufficient clearance for ISPR movement. 


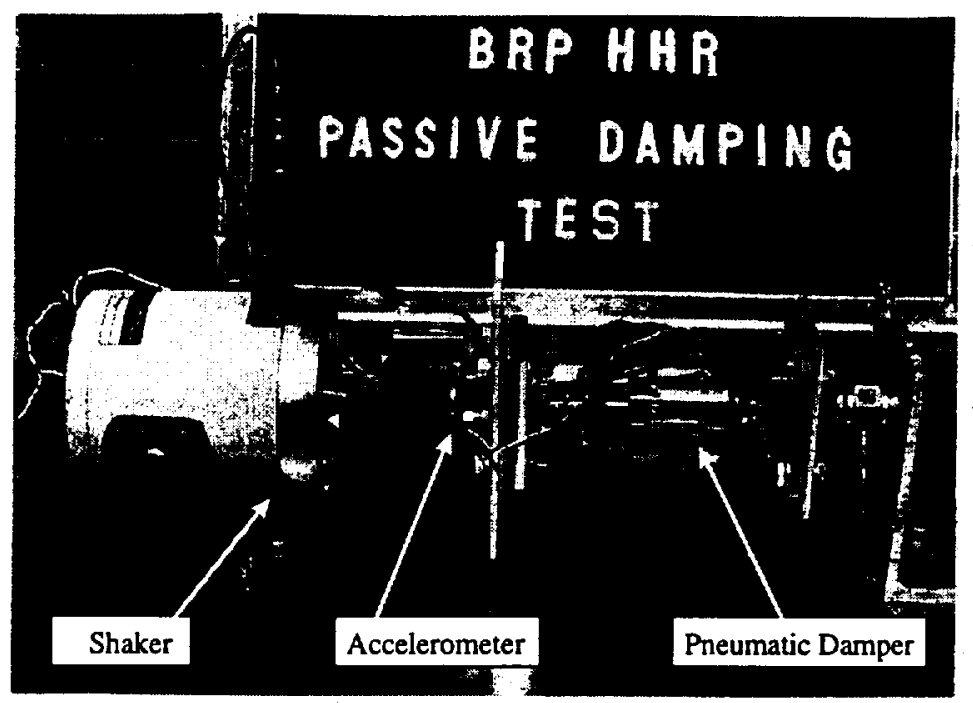

FIGURE 24. Developmental test set-up of PDS isolation unit employing a pneumatic damper and helical coil spring. Various instrumentation is identified in the illustration.

\section{Development Testing}

As part of the trade study, component level development testing was performed to confirm pneumatic damper performance at low velocities. Additional activities were completed to confirm helical coil spring and metal bellows stiffness properties. Isolation units were then constructed using the pneumatic dampers and springs tested, having properties similar to those needed for PDS units. Transmissibility measurements taken, for various input levels, were used to construct a predicted performance curve to characterize pneumatic damper performance over the frequency range of interest $(0.1$ to $100 \mathrm{~Hz})$. This information was then included in the PDS analytical simulations. The developmental test configuration used is illustrated in Figure 24.

\section{System Performance}

Based on PDS single-degree-of-freedom (SDOF) and multi-degree-of-freedom (MDOF) analytical modeling performed, along with supporting developmental testing information, PDS system performance has been predicted. Results showed that PDS isolation units with properties similar to those tested would provide the performance needed along all axes (See Figure 25). However, $Y$-axis PDS performance nearly exceeds the desired environment, mainly due to the increased stiffness along this axis due to umbilical assembly stiffness. Based on a payload rack mass of 1400 pounds $(635 \mathrm{~kg})$ and a minimum axial stiffness of $14 \mathrm{lb} /$ in $(2.45 \mathrm{kN} / \mathrm{m})$, PDS system resonance occurs at approximately $0.3 \mathrm{~Hz}$. This performance curve indicates the additional transmission of acceleration levels at the calculated PDS system resonance. Adding more damping to the system reduces system response at resonance, but increases transmitted acceleration levels at higher frequencies. Maximum ISPR deflection (amplitude) was calculated to be approximately 0.25 inch $(0.635 \mathrm{~cm})$ at an ISPR corner fitting. This "dynamic envelope" would allow two PDS outfitted ISPRs to be adjacently located within the available 0.5 inch $(1.27 \mathrm{~cm})$ structural gap between the payload racks, as well as clear all surrounding USL structure. 


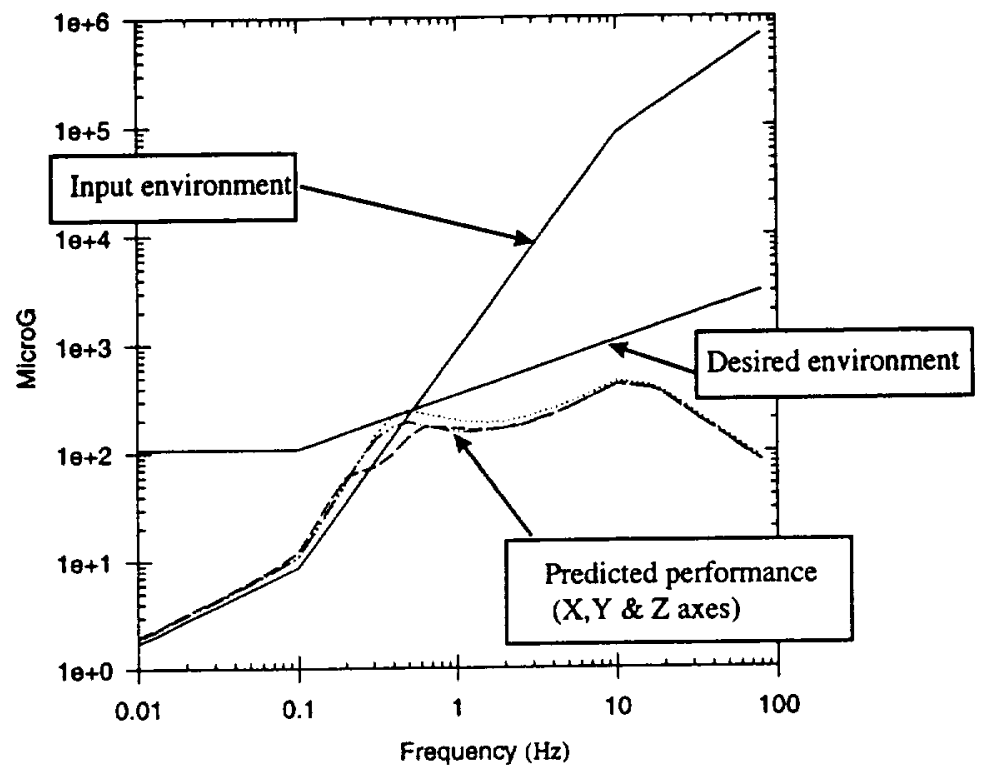

FIGURE 25. JOF modeling results for a specific PDS configuration utilizing the predicted properties of a pneumatic dar: Environment" isolation unit. "Input Environment" represents ISS vibration levels at assembly complete. "Desired resents HHR-experiment required acceleration levels. Y-axis transmitted accelerations are higher due to addition imbilical assembly stiffness.

\section{Summary}

Vibration iso on of ISS micro-gravity experiment payloads through a passive means has been determined to be feasible. i preliminary design has been developed and initial component testing performed. Analysis indicates effe. ve vibration isolation starting at slightly below $1 \mathrm{~Hz}$. The preliminary design requires no USL module : sign changes or ISPR utilities for isolation system operation. This Passive Damping System can also utili. : lock-down and snubbing hardware and ISPR utility umbilicals already designed for the active vibrati.:. isolation systems, to reduce program and development costs. The inherent "generic" design of the PDS re: further reduci: : costs. However, due to its relatively new application characteristics for ISS micro-gravity science, addi.nal work is still needed to confirm system performance and define PDS packaging. Additional component and system level testing is needed to support follow-on analytical MDOF simulations of both $2^{\text {nd }}$ or $:$ r and $3^{\text {rd }}$ order vibration isolation systems. As a result, an extensive development program is planned in $:$ :pport of PDS implementation for ISS operations.

\section{ACKNOWLEDGEMENTS}

The work on w'ich this paper is based has been performed by Boeing Defense \& Space Group for Marshall Space Flight $C: n t e r$, Huntsville, Alabama, on NASA contract NAS-50000. 